Original Article

\title{
THE INFLUENCE OF EDUCATION OF DRUG INFORMATION BY PHARMACIST ON THE IMPROVEMENT OF KNOWLEDGE AND THERAPEUTIC TARGET TO TYPE 2 DIABETES MELLITUS OUTPATIENTS IN HOSPITAL
}

\author{
PUJI ASMINI \\ Department of Pharmacology and Clinical Pharmacy in the Faculty of Pharmacy, Universitas Muhammadiyah Surakarta, Solo, Indonesia \\ Email: pujiasmini@ums.ac.id
}

Received: 25 Jun 2016 Revised and Accepted: 30 Jan 2017

\begin{abstract}
Objective: The study aims to determine the influence of education of drug information by the pharmacist on the improvement of knowledge and therapeutic target to type 2 diabetes mellitus outpatients in Dr. Moewardi Surakarta Hospital.

Methods: The research used the quasi-experimental method, repeated measure experiment design, pre-posttest design with the prospective patient data retrieval. 90 patients with type 2 diabetes mellitus were used as the subjects of the research divided into three groups (two test groups and one control group). In the test 1 group, patients were educated about the drug information through leaflets and through oral explanation, the test 2 group through leaflets, and a control group through leaflets once at the beginning of the study. The study lasted for three months in which in every month fasting blood glucose levels (FBG) and blood glucose levels were analyzed within two hours after a meal (BG2PP) and given questionnaires knowledge to see the socio-demographic profile, knowledge, and blood glucose level of the patient. The data analysis used the statistical package for social sciences (SPSS) version 16 in the form of analysis Kolmogorov-Smirnov test and one-way anova test.
\end{abstract}

Results: The results showed that the education of the drug information by a pharmacist using leaflets and oral explanation in the test 1 group was able to improve knowledge of type 2 diabetes mellitus outpatients in Dr. Moewardi Surakarta Hospital, in comparison to the leaflets giving information only to the test 2 group and control group. The education of drug information on the test 1 group was able to improve the patients' knowledge reaching $100 \%$. Type 2 diabetes outpatients in the test 1 group could achieve a reduction in blood sugar levels, to the FBG level (136.47 \pm 36.08$) \mathrm{mg} / \mathrm{dl}$ and BG2PP levels $(193.43 \pm 58.21) \mathrm{mg} / \mathrm{dl}$.

Conclusion: The education of drug information from the pharmacist had the influence to improves the knowledge and therapeutic target of type 2 diabetes mellitus outpatients in Dr. Moewardi Surakarta Hospital.

Keywords: Pharmacist education, Diabetes mellitus, Knowledge, Therapeutic targets

(C) 2016 The Authors. Published by Innovare Academic Sciences Pvt Ltd. This is an open access article under the CC BY license (http://creativecommons.org/licenses/by/4.0/) DOI: http://dx.doi.org/10.22159/ijpps.2017v9i3.13682

\section{INTRODUCTION}

Diabetes is justly recognized as an emerging global epidemic, representing one of leading cause of morbidity and mortality worldwide [1]. The prevalence of diabetes mellitus in Indonesia in 2013 was $6.9 \%$ of the total population, consist of $29.9 \%$ impair glucose tolerance and 36.6\% impair fasting glycaemia [2]. Diabetes is a chronic illness that requires continuing medical care and patient self-management education to prevent acute complications and to reduce the risk of long-term complications. Diabetic care is complex and requires that many issues, beyond glycaemic control, be addressed. Type 2 diabetes is frequently not diagnosed until complications appear, and approximately one-third of all people with diabetes may be undiagnosed. The incidence of type 2 diabetes in children and adolescents has increased dramatically in the last decade [3].

Diabetes patient education has long been recognised as a vital and integral component of successful diabetes care. However, complex and daily requirements such as medication taking and adjustment, self-monitoring of blood glucose, foot care, dietary modification and attendance for regular medical care place a psychological and financial burden on people with diabetes. Diabetes patient education for people with type 2 diabetes improves their knowledge and understanding [4]. Education involves enhancing skills and knowledge in order to bring about changes in related attitudes and behaviours [5]. Pharmacist are often called upon to provide education to patients and other health care providers about medications. Pharmacist process to improve continuity of care, outcomes, and outcome measures [6]. Patieny education has been found to contribute to improving self-care and metabolic control of patients with diabetes. A system such therapeutic outcome monitoring is a way for providing pharmaceutical care in an ambulatory setting that emphasize the role of the pharmacist in addressing a major cause of preventable drug-related morbidity [7]. In 2011, diabetes mellitus was in the fifth rank in the top 10 disease hospitalisation in Dr. Moewardi Surakarta Hospital. The data of diabetic patients in 2013 showed that there were 70 people per day. The patients were with a routine control and some are able to reach therapeutic targets, and some cannot reach therapeutic targets [8].

\section{MATERIALS AND METHODS}

The research used a quasi-experimental study. The research has been approved by Medical and Health Research Ethics Committee (MHRC) Faculty of Medicine Gadjah Mada University-Dr Sardjito General Hospital. The design study was a repeated measure preposttest design involving three groups and conducting a series of tests on the test groups or the control group; both before and after the tets. The research was conducted on three groups. The groups comprised of test 1 group, test 2 group, and control group. Intervention given to the first group was about the education of drug information by pharmacists using leaflets and oral as the test 1 group. While other intervention were given in the test 2 group by using leaflet three times at the following study, and in the control group only using leaflet at the beginning study. This research was conducted in the outpatient pharmacy installation at Dr. Moewardi Hospital on June-August 2014. The subjects of this study were all patients diagnosed with type 2 diabetes mellitus with or without comorbidities illness, and routine visit once in a month. The instrument used in this study was a questionnaire of knowledge gained from a journal entitled "Evaluation of The Patient's Antidiabetic 
Medication Counselling provided by Pharmacists in a Tertiary Health Care Setting in Nigeria [9]. The research observed the characteristics of socio-demographic and knowledge of drugs patient (information on which sources of drug information where patient purchased medicines, patients' knowledge of diabetes medicine's name, the goal of therapy, dosage/frequency therapy, side effects, duration of therapy, and patients's adherence).

The data analysis was presented in tables or diagrams and calculated the frequency and percentage of diabetic patients by sex, marital status, age, education level, occupation, duration of diabetes, and complication disease. The analysis of data on knowledge used the Statistical Package for Social Sciences (SPSS) version 16.0 and on patient knowledge, it used a 2-point likert scale, yes scored 2, no scored 1 and no response scored 0 . The knowledge of diabetes mellitus drug measured from answers to questions on the questionnaire knowledge no. 4, 5, 6, and 7. An appropriate research was obtained by Onkoro et al. [9] included whether patients with type 2 diabetes know the name of the medicine, and the reason why taking medicine, the dosage or frequency of medicine's administration, and common side effects of the medicine. The level of knowledge of drugs was judged into two categories: know and do not know. The measurement was obtained from the answers to the questionnaire knowledge no. 4, 5, 6, 7, 8, and 9. Each answer of yes scored 2, no scored 1 , and did not respond scored 0 . The accumulated score was divided into categories into know and do not know. Patients with the category know is those obtaining a score of $\geq 11$, and the ones with the category do not know were those obtaining a score of $<11$. The number of patients was categorized into two aspects: know and do not know, numbered. Here, the statistical analysis used Kolmogorov-smirnov test to observe the differences in knowledge between groups in pre-post research. Data of blood sugar levels within 3 mo of the study, consisting of fasting blood sugar levels and two hours after eating were ratio scale, were analyzed using one-way anova test to see the differences in blood sugar levels between the groups.

\section{RESULTS}

Knowledge questionnaire provided information about the characteristics of the subjects and the level of patients' knowledge about drugs. The study involved 90 type 2 diabetes mellitus outpatients and their demographic (table 1). This research was obtained from the mean age of our participants in the control group was 56.36 y old, test 1 group was 57.00 y old, and test 2 group was $58.13 \mathrm{y}$ old. It was observed that most participants was female $(60 \%$ in the control group, $46.7 \%$ in the test 1 group, $53.3 \%$ in the test 2 group), their most patient's occupation was a housewife $(36.7 \%$ in all groups), and educated below senior high school (30\% in the control group, $46.7 \%$ in the test 1 group, $56.7 \%$ in the test 2 group).

Table 1 also showed that most of the patients were married (90\% in the control group and test 2 group, $100 \%$ in the test 1 group), overweight ( $40 \%$ in the control group, $30 \%$ in the test 1 group, $46.7 \%$ in the test 2 group), and having commorbidities illnes $(93.3 \%$ in the control group, $80 \%$ in the test 1 group, $83.3 \%$ in the test 2 group). Our subjects have been diagnozed with type 2 diabetes mellitus for more than 4 y. Patients also had co-morbidies illnes, 93.3\% in the control group, $80 \%$ in the test 1 group, and $83.3 \%$ in the test 2 group.

Table 1: Demographic characteristic of subjects $(n=90)$

\begin{tabular}{|c|c|c|c|c|c|}
\hline \multirow[t]{2}{*}{ No } & \multirow[t]{2}{*}{ Characteristic } & \multirow{2}{*}{$\begin{array}{l}\text { Control }(\mathrm{N}=30) \\
\mathrm{n}(\%)\end{array}$} & \multicolumn{2}{|c|}{ Test group $1(\mathrm{~N}=30) 2(\mathrm{~N}=30)$} & \multirow{2}{*}{$\begin{array}{l}\text { Significance } \\
\mathbf{P}\end{array}$} \\
\hline & & & n (\%) & n (\%) & \\
\hline \multirow[t]{3}{*}{1} & Gender & & & & \\
\hline & Male & $12(40.0)$ & $16(53.3)$ & $14(46.7)$ & \\
\hline & Female & $18(60.0 \%)$ & $14(46,7)$ & $16(53.3)$ & *0.996 \\
\hline \multirow[t]{5}{*}{2} & Age (years) & & & & \\
\hline & $40-49$ & $4(13.3)$ & $3(10.0)$ & $2(6.7)$ & \\
\hline & $50-59$ & $17(56.7)$ & $16(53.3)$ & $15(50.0)$ & \\
\hline & $60-65$ & $9(30.0)$ & $11(36.7)$ & $13(43.3)$ & \\
\hline & mean $\pm S D$ & $56,36 \pm 5,85$ & $57,00 \pm 5,89$ & $58,13 \pm 4,98$ & $* 0.223$ \\
\hline 3 & Duration of diabetes (years), mean \pm SD & $5.48 \pm 3.8$ & $4.73 \pm 3.7$ & $4.50 \pm 2.29$ & $* 0.498$ \\
\hline \multirow[t]{8}{*}{4} & Employment status & & & & \\
\hline & Civil servant & $6(20.0)$ & $3(10.0)$ & $6(20.0)$ & $* 0.321$ \\
\hline & Retired & $7(23.3)$ & $8(26.7)$ & $11(36.7)$ & \\
\hline & Employee & $3(10.0)$ & $3(10.0)$ & $1(3.3)$ & \\
\hline & Bussinesman & $3(10.0)$ & $1(3.3)$ & $0(0.0)$ & \\
\hline & Trader & $0(0.0)$ & $1(3.3)$ & $1(3.3)$ & \\
\hline & Farmer & $0(0.0)$ & $1(3.3)$ & $0(0.0)$ & \\
\hline & Housewife & $11(36.7)$ & $11(36.7)$ & $11(36.7)$ & \\
\hline \multirow[t]{4}{*}{5} & Education status & & & & \\
\hline & Up to senior high school & $6(20.0)$ & $6(20.0)$ & $7(23.3)$ & $* 0.223$ \\
\hline & Senior high school & $15(50.0)$ & $8(26.7)$ & $6(20,0)$ & \\
\hline & Below to senior high school & $9(30.0)$ & $14(46.7)$ & $17(56.7)$ & \\
\hline \multirow[t]{4}{*}{6} & Marital status & & & & \\
\hline & Married & $27(90.0)$ & $30(100.0)$ & $27(90.0)$ & $* 0.261$ \\
\hline & Single & $0(0.0)$ & $0(0.0)$ & $1(3.3)$ & \\
\hline & Widow/er & $3(10.0)$ & $0(0.0)$ & $2(6.7)$ & \\
\hline \multirow[t]{6}{*}{7} & Body mass index & & & & \\
\hline & Underweight $(<18,5)$ & $1(3.3)$ & $0(0.0)$ & $0(0.0)$ & $* 0.287$ \\
\hline & Ideal $(18,5-22,9)$ & $8(26.7)$ & $5(16.7)$ & 5 (16.7) & \\
\hline & In risk $(23.0-24,9)$ & $8(26.7)$ & $13(43.3)$ & 8 (26.7) & \\
\hline & $\begin{array}{l}\text { Overweight } \\
(25,0-29,9)\end{array}$ & $12(40.0)$ & $9(30.0)$ & $14(46.7)$ & \\
\hline & Obese $(>30)$ & $1(3.3)$ & $3(10.0)$ & $1(3.3)$ & \\
\hline \multirow[t]{3}{*}{8} & Comorbidity & & & & \\
\hline & Yes & $28(93.3)$ & $24(80.0)$ & $25(83.3)$ & \\
\hline & No & $2(6.7)$ & $6(20.0)$ & $5(16.7)$ & \\
\hline
\end{tabular}

${ }^{*} \mathrm{p}<0.005-$ significant, SD: standard deviation

In this research, our subject had diabetes comorbidities. In this research, patients diagnosed comorbid of type 2 diabetes mellitus with hypertension $(\geq 20 \%)$ and neuropathy $(\geq 20 \%)$. Following hypertension and neuropathy, dyslipidemia was also sufferred by type 2 diabetes mellitus outpatients at $3.3 \%-16.67 \%$. 
Table 2: Type of diabetes comorbidity

\begin{tabular}{llll}
\hline Disease & Control $(\mathbf{N}=\mathbf{3 0}) \mathbf{n}(\mathbf{\%})$ & Test 1 (N=30) n (\%) & Test 2 (N=30) $\mathbf{n}(\%)$ \\
\hline Hypertension & $8(26,7)$ & $6(20,0)$ & $8(26,7)$ \\
Dyslipidemia & $5(16,7)$ & $5(16,7)$ & $1(3,3)$ \\
Neuropathy & $6(20,0)$ & $6(20,0)$ & $10(33,3)$ \\
\hline
\end{tabular}

In table 3 showed that one of the most widely prescribed drugs was anti-hypertensive drugs, particularly angiotensin receptor blocker class (43.3\%). While neurotropic prescribed $80 \%$.

In tabel $4,100 \%$ of patients with type 2 diabetes obtained metformin, as the first drug of choice for treatment of diabetes mellitus type 2 , followed by acarbose (72\%) and gliquidone (64\%). Rapid insulin acting was prescribed at $61.1 \%$. In table 5 , it was found that the largest percentage as a source of information medication, were physicians at $84.4 \%$, followed by the pharmacist/pharmacist assistant with $3.3 \%$, medical sales $2.2 \%$, and no receiving information $9.9 \%$.

Table 3: The use of drug use for comorbidity of type 2 diabetes

\begin{tabular}{lllll}
\hline Drug & Control (N=30) & Test1 (N=30) & Test2 (N=30) & $\begin{array}{l}\text { Total (N=90) } \\
\mathbf{n}(\%)\end{array}$ \\
\hline Antihypertensive drug & $\mathbf{N}$ & $\mathbf{N}$ & & $39(43.3)$ \\
ARB & & & 15 & \\
CCB & 15 & 9 & 13 & $36(40.0)$ \\
ACE-I & 13 & 10 & 4 & $13(14.4)$ \\
Diuretic & 4 & 5 & 5 & $15(16.7)$ \\
B Blocker & 5 & 5 & 1 & $13(14.4)$ \\
Neurotropic & 1 & 11 & 27 & $80(88.9)$ \\
NSAID & 27 & 26 & 12 & $33(36.7)$ \\
Statin & 12 & 9 & 9 & $24(26.7)$ \\
Dopamine Antagonis & 9 & 4 & 2 & $8(8.9)$ \\
Nitrate & 2 & 1 & 2 & $5(5.5)$ \\
Antihistamine & 2 & 2 & 3 & $8(8.9)$ \\
Fibrate & 3 & 1 & 2 & $5(5.5)$ \\
\hline
\end{tabular}

ARB: Angiotensin receptor blocker, CCB: Calcium channel blocker, ACE-I: Angiotensin converting enzyme inhibitor, NSAID: Non-steroidal inflammatory drugs

Table 4: Antidiabetic oral and injection

\begin{tabular}{|c|c|c|c|c|}
\hline \multirow[t]{2}{*}{ Name of drug } & \multicolumn{4}{|l|}{ Subject } \\
\hline & $\begin{array}{l}\text { Control } \\
(n=30)\end{array}$ & $\begin{array}{l}\text { Test } 1 \\
(n=30)\end{array}$ & $\begin{array}{l}\text { Test } 2 \\
(n=30)\end{array}$ & $\begin{array}{l}\text { Total }(\mathrm{N}=90) \\
\text { n }(\%)\end{array}$ \\
\hline Metformin & 31 & 30 & 29 & $90(100.0)$ \\
\hline Acarbose & 24 & 25 & 23 & $72(80.0)$ \\
\hline Gliquidone & 22 & 20 & 22 & $64(71.1)$ \\
\hline Glimepirid & 8 & 7 & 6 & $21(23.3)$ \\
\hline Pioglitazone & 3 & 3 & 3 & $9(10.0)$ \\
\hline Rapid acting insulin & 16 & 18 & 21 & $55(61.1)$ \\
\hline Long actinginsulin & 3 & 7 & 6 & $16(17.8)$ \\
\hline Intermediate acting & 3 & 3 & 3 & $9(10.0)$ \\
\hline
\end{tabular}

Table 5: Patient source for anti-diabetic information

\begin{tabular}{lll}
\hline Question source & Total (N=90) n (\%) \\
\hline Who provide drug information? & None & $4(4.4)$ \\
& Physicians & $76(84.4)$ \\
& Pharmacist/Pharmacist assistant & $3(3.3)$ \\
& Medical Sales & $2(2.2)$ \\
\hline
\end{tabular}

Knowledge of type 2 diabetic mellitus outpatients at the beginning of the study is presented in table 6 including:

1. Knowledge of test 1 group, patients, understand on the purpose of drug, and the dose/frequency reached $\geq 80 \%$, while they only understand on the side effects of drugs $50 \%$.

2. Knowledge of control and test 2 group, patients, understand on the name of the drug, the purpose of treatment, and the dose/frequency reached $\geq 90 \%$, while the patients who only understand the side effects of drug was still low (60\%)

3. It was only $70 \%$ of patients in the test 1 group who know about the name of the drugs, otherwise $90 \%$ in the control group and 83.3 $\%$ in the test 2 group.
In table 7, the influence of drug information education was analyzed by statistical analysis of the level of knowledge among groups of patients after intervention by using the Kolmogorov-Smirnov obtained by value $p=0.100$. it can be concluded that there was no any significant difference between groups before and after the education of the drug information pharmacist ( $p>0.05)$. Based on the distribution of patient in each group, the test 1 group, show improvement knowledge from $56.7 \%$ up to $100 \%$. Otherwise in the control group was only up $70 \%$ to $100 \%$ and in the test 2 group was only up $70 \%$ to $90 \%$.

Blood glucose levels were obtained every month containing the fasting blood glucose levels (FBG) and blood glucose levels within two hours after a meal (BG2PP). In table 8, showed that the education of drug information from the pharmacist in the test 1 
groups can help patients with diabetes achieve better therapeutic outcomes rather than test 2 group and the control group. BG2PP and FBG level's patients in the test group 1 decreased significantly. Blood glucose level in type 2 diabetes outpatient in the test 1 group had a significant decrease in the fasting blood glucose from $177,27 \pm 68,86$ drop to $136,47 \pm 36,08(\mathrm{mg} / \mathrm{dl})$ and blood glucose within $2 \mathrm{~h}$ after meal, $256,47 \pm 102,82$ drop to $193,43 \pm 58,21$ (mg/dl). While the level of FBG and BG2PP in the test 2 group and control were only decreased slightly. The statistical analysis of the blood sugar glucose levels of patients between groups after being given intervention by using one-way ANOVA showed the value $\mathrm{p}=0.404$ for $\mathrm{FBG}=0.694$ for BG2PP. Here, it can be concluded that there was no significant difference in blood glucose levels between groups before and after the education of drug information pharmacist.

Table 6: Knowledge on anti-diabetic's drug

\begin{tabular}{|c|c|c|c|c|c|c|}
\hline \multirow[t]{2}{*}{ Knowledge } & \multicolumn{2}{|c|}{ Control $(\mathrm{N}=30)$} & \multicolumn{2}{|c|}{ Test $1(\mathrm{~N}=30)$} & \multicolumn{2}{|c|}{ Test $2(\mathrm{~N}=30)$} \\
\hline & Yes n (\%) & No n (\%) & Yes n (\%) & No n (\%) & Yes n (\%) & No n (\%) \\
\hline Name of anti-diabetic & $27(90.0)$ & $3(10.0)$ & $21(70.0)$ & $9(30.0)$ & $25(83.3)$ & 5 (16.7) \\
\hline Purpose of medication & $29(96.7)$ & $1(3.3)$ & $26(86.7)$ & $4(13.3)$ & $30(100.0)$ & $0(0.0)$ \\
\hline Dosage or frequency & $29(96.7)$ & $1(3.3)$ & $24(80.0)$ & $6(20.0)$ & $28(93.3)$ & $2(6,7)$ \\
\hline Side effect & $18(60.0)$ & $12(40.0)$ & $15(50.0)$ & $15(50.0)$ & $18(60.0)$ & $12(40.0)$ \\
\hline
\end{tabular}

Table 7: The effect of drug information education to patient's knowledge

\begin{tabular}{|c|c|c|c|c|}
\hline Description/Phase & Control $(\mathrm{N}=30)$ & Test $1(\mathrm{~N}=30)$ & Test $2(\mathrm{~N}=30)$ & Significance $\mathbf{P}$ \\
\hline 1. Understand & $\begin{array}{l}\text { Understand } \\
\mathrm{n}(\%)\end{array}$ & $\begin{array}{l}\text { Understand } \\
\mathrm{n}(\%)\end{array}$ & $\begin{array}{l}\text { Understand } \\
\mathrm{n}(\%)\end{array}$ & $0.100^{* *}$ \\
\hline Baseline & $21(70.0)$ & $17(56.7)$ & $21(70.0)$ & \\
\hline Final follow up (after $3 \mathrm{mo}$ ) & $30(100.0)$ & $30(100.0)$ & $27(90.0)$ & \\
\hline 2. Not understand & $\begin{array}{l}\text { Not Understand } \\
\mathrm{n}(\%)\end{array}$ & $\begin{array}{l}\text { Not Understand } \\
\mathrm{n}(\%)\end{array}$ & $\begin{array}{l}\text { Not Understand } \\
\mathrm{n}(\%)\end{array}$ & \\
\hline Baseline & $9(30.0)$ & $13(43.3)$ & $9(30.0)$ & \\
\hline Final follow up (after $3 \mathrm{mo}$ ) & $0(0.0)$ & $0(0.0)$ & $3(10.0)$ & \\
\hline
\end{tabular}

${ }^{* *} \mathrm{p}<0.05$ highly significant

Table 8: Blood glucose levels

\begin{tabular}{llll}
\hline Characteristic & Control group & Test 1 & Test 2 \\
\cline { 2 - 3 } & $\mathbf{n = 3 0}$ & $\mathbf{n = 3 0}$ & $\mathbf{n}=\mathbf{3 0}$ \\
\hline FBGbaseline, mean \pm SD $(\mathrm{mg} / \mathrm{dl})$ & $176,83 \pm 71,86$ & $177,27 \pm 68,86$ \\
FBG final follow up (after 3 mo), mean \pm SD (mg/dl) & $195,20 \pm 79,06$ & $136,47 \pm 36,08$ \\
BG2PPbaseline, mean \pm SD (mg/dl) & $245,80 \pm 103,08$ & $256,47 \pm 102,82$ & $182,33 \pm 78,00$ \\
BG2PP final follow up (after 3 mo), mean \pm SD (mg/dl) & $246,27 \pm 101,98$ & $193,43 \pm 58,21$ \\
\hline
\end{tabular}

$\mathrm{p}<0.005$-significant, SD: Standard deviation

\section{DISCUSSION}

In this study, we demonstrated that type 2 diabetic outpatients had characteristic had a liniear data with some previous studies. There was no statistically significant difference in all characteristic subjects among the groups ( $p>0.05)$. In this research obtained data that type 2 diabetes mellitus outpatients had mean of age was at age $56,36 \pm 5,85$ y old in the control group, $57,00 \pm 5,89$ y old in the test 1 group, and $58,13 \pm 4,98$ y old in the test 2 group. Duration of diabetes mellitus was in $5.48 \pm 3.8 \mathrm{y}$ in control group, $4.73 \pm 3.7 \mathrm{y}$ in the test 1 group, and $4.50 \pm 2.29 \mathrm{y}$ in the test 2 group. Education status also showed that below senior high school (primary school and below) was prominent education among the subject about $30 \%$ in the control group, $46.7 \%$ in the test 1 group, and $56.7 \%$ in the test 2 group. This observation was found to be similar made by Renuga et al. [10]. The mean age of test group $57 \pm 9.878$ and control group was $57 \pm 9.438$; the mean duration of diabetes mellitus in the control group $5.79 \pm 3.5 \mathrm{y}$; and the most education level of patients was $64 \%$ had done primary high school and below in control group and 51.5 $\%$ in the test group [10]. In our research obtained that most of type 2 diabetes outpatient had employed as a housewife at $36,7 \%$ in all groups. A similar study Ramesh et al. [11] had observed that an occupation of subjects was mostly housewife at $37.4 \%$. This research found that the most participant was overweight at $40 \%$ in the control group, $30 \%$ in the test 1 group, and $46.7 \%$ in the test 2 group. Marhanis et al. [12] had observed that most participants was overweight $(43.5 \%)$. In this research also showed that type 2 diabetes outpatients had diagnozed with complication at $93.3 \%$ in the control group, $80 \%$ in the test 1 group, and $83.3 \%$ in the test 2 group. It is supported by previous studies, by Sesilia et al. [13] showed that type 2 diagnozed with complication at $79.75 \%$.

Based on this research, the most of commorbid disease to diabetes mellitus are hypertension at $26.7 \%$ in the control group, $20 \%$ in the test 1 group, and $26.7 \%$ in the test 2 group. Followed by neuropathy and dyslipidemia. Sharad et al. [14] had observed that most of the subject had hypertension as commorbid illness $(38.12 \%)$ at most. Diabetic complication are the challenges associated with diabetes in the form of micro, and macrovascular complication includes retinopathy, nephropathy and neuropathy whereas macrovascular complication includes coronary artery disease, peripheral vascular disease, and cerebrovascular events [15]. Type 2 diabetes and hypertension are commonly co-occuring conditions, approximately $70 \%$ of patients with type 2 diabetes are diagnosed with hypertension. Both conditions gradually damage vascular system, and when left unmanaged can result in debilitating long-term complication including cardiovascular disease, neuropathy, kidney damage, and retinopathy [16].

Antihypertension drugs prescribed in this research are angiotensin receptor blocker class (ARB) 43.3\%, calcium channel blockers (CCB) $40 \%$, diuretic $16.7 \%$, $\beta$-blocker $14.4 \%$, and angiotension converting enzyme (ACE) inhibitors 14,4\%. Initial hypertension therapy with diabetes may be with ACE inhibitors, ARB, $\beta$-blocker, or diuretics. Particularly, ACE inhibitors and ARBs are considered first-line therapy for the prevention of and progression of nephropathy (ADA). In line with Supratim et al. [17] showed (ACE) inhibitors and ARB's were prescribed in $45 \%$ patients with diabetes and $21 \%$ in 
diabetes associated nephropathy. CCB's was prescribed in $60 \%$ patients with diabetes and $95 \%$ in diabetes associated nephropathy.

The research found that the $100 \%$ type 2 diabetes mellitus patients were prescribed metformin. Similar with Yasser et al. [18] obtained that metformin monotherapy are effective as an initial treatment of newly diagnozed diabetic patients, in the national diabetic center/University of Al Mustansiriyah, Iraqi. Metformin had a significant reduction effect on three groups, had a significant reduction in $\mathrm{HbA1C}$ and also a significant reduction in cytocines in three dose in different percent. Besides metformin, acarbose was used for patients with type 2 diabetes those were for 72 people $(80$ $\%)$. In type 2 diabetic patients, acarbose should be the preferred monotherapy for early disease stages with high postprandial blood glucose levels to enable patients to benefit from its pronounced effect on postprandial blood glucose [9]. In advanced type 2 diabetes, acarbose can be combined with all other antidiabetic agents and has favorable effects on the side effects of other drugs, such as body weight increase or hypoglycemic episodes. Antidiabetic therapies with a strong impact on fasting blood glucose should be preferred in combination [19]. Insulin therapy is indicated in the treatment of type 2 diabetes for initial therapy of severe hyperglycemia, after the failure of oral agents, or during perioperative or other acute hyperglycemic states [20]. As indicated by haghighatpanah et al. [21] intensive glycemic control by insulin therapy may help to delay or prevent the progression of diabetic macrovascular and microvascular. The correct dosage of insulin could lower HbA1C levels to reach therapeutic targets. The combination with insulin is the most potent treatment for lowering blood glucose levels.

Clear and accurate information related to the use of medication could be obtained from health professionals, capable of improving knowledge in therapy. In this research, showed that type 2 diabetic outpatients obtained the drug information from a physician at $76 \%$. Ashry et al. [22] also obtained that physician was the most common source of medication information.

The most knowledge of patient is the purpose of medication. This research was linear with research conducted by Ramesh et al. [11], showed that $76.2 \%$ patient know the reason to take medication. Otherwise, the lowest knowledge of the patient was a side effect of medicine. In this research, the patient's knowledge level was only low in the knowledge of side effects. After being given an explanation at the beginning of the meeting, the patient understands about the drug name, the reason for taking the drug, dose or frequency, side effects of medication, and forget to take medication. It is related to Gad et al. [22] observed that patient did not receive a medication's instructions from a physician about 78.5\%; otherwise, physicians provide instruction's medication about the name of the medication $(70.5 \%)$, dosage $(80.3 \%)$, and duration of each medication intake $(82.9 \%)$. In our study, the education of drug information by pharmacist could improve knowledge about drug's name, target, dose/frequency, and side effects. In the end of the study, type 2 diabetic outpatient understood the knowledge of the drug at $90 \%-100 \%$.

The influence of drug information education to knowledge enhancement was analized by statistical analysis showed that there was no any significant difference between groups before and after education of the medication information pharmacist $(p>0.05)$, but based on amount of patient in each group, the test 1 group, show improvement knowledge from $56.7 \%$ up to $100 \%$ (table 7 ). This is consistent with the previous studies by Renuga et al. [10] on the last follow-up, the knowledge, attitude, and practice's score was increased for both the groups but the improvement was significantly higher for the intervention group patients when compared to the control group due to continuous patient counselling.

In table 8, it can be concluded that the education of drug information from the pharmacist in the test 1 groups can help patients with diabetes achieve better therapeutic outcomes rather than the test 2 group and the control group. BG2PP and FBG level's patients in the test group 1 decreased significantly. Although, the statistical analysis of the blood sugar glucose levels of patients between groups after being given intervention by using one-way anova concluded that there was no significant difference in blood glucose levels between groups before and after the education of a drug information by the pharmacist $(p>0.05)$. Base on decreasing level of blood glucose in each group, patient in the test 1 group show a significant decrease in the fasting blood glucose from $177,27 \pm 68,86$ to $177,27 \pm 68,86$ (mg/dl) and blood glucose within $2 \mathrm{~h}$ after meal, 256,47 $\pm 102,82$ to $193,43 \pm 58,21$ (mg/dl). A similar study was conducted by Ramesh $e t$ al. [11] assessed improvement in the capillary blood glucose (CBG) level after the patient education. The significant improvement seen in the test group due to the practice the recommended lifestyle modification and self-management strategies.

\section{CONCLUSION}

Based on the research, there was a significant influence of drug information education by a pharmacist to type 2 diabetes mellitus outpatients in Dr. Moewardi Surakarta Hospital. The education could improve knowledge and achieve the therapeutic targets in the test 1 group, which was given the drug information using the media of leaflets and oral education by a pharmacist. The influence of education of drug information in the test 1 group could improve patients' knowledge by $100 \%$ and achieved a therapeutic outcome. Outcome of therapy in the test 1 group decreased, either on the fasting blood glucose (FBG) or in blood sugar $2 \mathrm{~h}$ after a meal (GB2PP), with the initial levels of FBG $(177.27 \pm 68.86) \mathrm{mg} / \mathrm{dl}$; BG2PP $(256.47 \pm 102.82) \mathrm{mg} / \mathrm{dl}$, decreased to $\mathrm{FBG}(136.47 \pm 36.08) \mathrm{mg} / \mathrm{dl}$; BG2PP levels (193.43 \pm 58.21$) \mathrm{mg} / \mathrm{dl}$

\section{CONFLICT OF INTERESTS}

\section{Declared none}

\section{REFERENCES}

1. Konstatenos P, Marciej B, Michael E, Nikolas P, Dimitrios P. Complication of diabetes. J Diabetes Res 2015;1-5. http://dx.doi.org/10.1155/2015/189525

2. Anon. Diabetes study and analysis. Data and Information Center of Indonesian Ministry of Health; 2014. p. 2-4.

3. Anon. Standards of medical care in diabetes. Diabetes Care 2005;28 Supp I:4-36.

4. Colagiuri R, Griffith R. National evidence-based guideline for patient education in type 2 diabetes The University of Sydney: Commonwealth of Australia; 2009.

5. Melanie JR. The pharmacist is talking with patients, a guide to patient counselling. British Columbia: William and Willkins Waverly Company; 1997. p. 105-6.

6. Patricia A, Richard C, Ken H, Jeannell M, Darryl R. The pharmacist's role patient safety. Illinois: Department of Publication Joint Commission Resources; 2007. p. 1-17.

7. Andrew LW. Managing the patient with type II diabetes. Maryland: Aspen Publishers, Inc; 1997. p. 45-7.

8. Anon. Dr Moewardi Surakarta annual report in 2013. Data and Information Center of Dr Moewardi Surakarta Hospital; 2014. p. 3-7.

9. Okoro RN, Ngong CK. Evaluation of patient's antidiabetic medication counseling provided by a pharmacist in a tertiary health care setting in Nigeria. Int Res J Pharm 2012;3:319-23.

10. Renuga E, Ramakrisnan SR, Vanitha RN, Thennasrasu P, Kannan G. Impact of continuous patient counselling on knowledge, attitude, and practice and medication adherence of diabetic patients attending outpatient pharmacy services. Asian J Pharm Clin Res 2016;9:364-9.

11. Ramesh A, Somashekar MA. Influence of structured patient education on therapeutic outcomes in diabetes and hypertensive patients. Asian J Pharm Clin Res 2010;3:174-8.

12. Marhanis SO, Kong LS. Diabetes knowledge and medication adherence among geriatric patient with type 2 diabetes mellitus. Int J Pharm Sci 2014;6:103-6.

13. Sesilia AK, Devi M. Antidiabetic drug use evaluation and drugrelated problems (DRPs) in type 2 diabetes mellitus outpatient at Jakarta Hospital (abstract for II-Indonesian Conference on Clinical Pharmacy). Asian J Pharm Clin Res 2016;9:1-8.

14. Sharad T, Jayesh KR, Kajal S. Assesmet of the quality of life in patients of type 2 diabetes using the diabetes-39 questionnaire. Innovare J Health Sci 2016;4:3-5. 
15. Deepraj P, Karthika P. Diabetes mellitus and its complications: a review. Int J Curr Pharm Res 2012;4:12-7.

16. Cara D, Erinmacpherson, Julie R. Effectiveness of telephonedelivered interventions for increasing physical activity levels in persons with type 2 diabetes or hypertension: a systematic review. J Crit Rev 2015;2:6-11.

17. Supratim DALU. Antihypertensive drug use in patients having comorbid diabetes: cross-sectional prescription pattern study in a tertiary care hospital. Asian J Pharm Clin Res 2010;3:43-5.

18. Yasser MK, Abbas MR, Saba HM. The effect of metformin on cytokines in Iraqi patients with type 2 Diabetes. Innovare J Medical Sci 2013;1:4-10.

19. Cristop R, Gabriele M. Critical evaluation of the role of acarbose in the treatment of diabetes: patient consideration. Dovepress J 2012;5:357-67.
20. Richard JM, Michael LA. Type 2 diabetes mellitus: update on diagnosis, pathophysiology, and treatment. JCE and M 2009;8:1165-71.

21. Mohamad H, Grish T, Ateendra J, Surulivelrajan M. Study on prescribing pattern of anti-diabetic drugs among type 2 diabetes patients with complication in South Indian Teaching Hospital. Asian J Pharm Clin Res 2016;9:194-7.

22. Ashry G, Saud A, Mohanned S, Ali A, Azzam A, Meshari A, et al. Physicians's instructions to patients regarding medications in Saudi University Hospital. Sci Res 2015;7:1441-7.

\section{How to cite this article}

- Puji Asmini. The influence of education of drug information by the pharmacist on the improvement of knowledge and therapeutic target to type 2 diabetes mellitus outpatients in the hospital. Int J Pharm Pharm Sci 2017;9(3):199-204. 